\title{
Analisis Sifat Fisik dan Mekanik Poros Berulir (Screw) Untuk Pengupas Kulit Ari Kedelai Berbahan Dasar Aluminium Bekas dan Piston Bekas
}

\author{
Andika Wisnujati ${ }^{1, a}$ dan Lalu Alpan Hafiz ${ }^{1}$ \\ ${ }^{1}$ Program Studi D3 Teknik Mesin, Program Vokasi Universitas Muhammadiyah Yogyakarta \\ Jl. Lingkar Selatan, Tamantirto, Kasihan, Bantul, DIY \\ ${ }^{\mathrm{a}}$ E-mail : andika_wisnujati@yahoo.com
}

\begin{abstract}
Aluminum alloys in this study using a mixture of aluminum profiles and former piston. Former piston is used to get the high enough of element $\mathrm{Si}$. The addition of $\mathrm{TiB}$ element (Titanium-Boron) as much as $0.02 \%$ at the time of casting expected to improve the mechanical and physical character of aluminum, so that expected the aluminum alloy has a strength that is much better than without the addition of any element. Aluminum alloy to manufacture screw will be casted by using sand molds on three types of variations mold temperature $200^{\circ} \mathrm{C}$, $300^{\circ} \mathrm{C}$ and $400^{\circ} \mathrm{C}$. The Test were conducted to determine the mechanical properties of the aluminum alloy and physical that are : tensile test, hardness test, and metallographic with an optical microscope. The maximum test result occurred in $\mathrm{Al}-\mathrm{Si}$ alloy material with $\mathrm{TiB}$ addition $0.02 \%$ and a heating temperature mold $400^{\circ} \mathrm{C}$ produces maximum tensile stress of 628.86 N/ $\mathrm{mm}^{2}$, while for Vickers Hardness Number (VHN) gives the figure of $114 \mathrm{~kg} / \mathrm{mm}^{2}$; and for the results obtained from the data metallographic structure formed hypereutectic silicon which form the primary silicon phase. That phase provides high wear resistance. Finally, it is evident that the Al-Si alloys mentioned above can improve the properties of aluminum to manufacture a screw.
\end{abstract}

Keywords-Aluminum Alloy, Screw, Mechanical and Physical properties

Abstrak - Aluminium paduan pada penelitian ini menggunakan campuran Aluminium profil dan piston bekas. Piston bekas digunakan untuk mendapatkan unsur Si yang cukup tinggi pada piston. Penambahan unsur TiB (Titanium-Boron) sebanyak $0,02 \%$ pada saat pengecoran diharapkan mampu memperbaiki sifat-sifat mekanis dan fisis aluminium sehingga diharapkan aluminium paduan ini memiliki kekuatan yang jauh lebih baik dibandingkan tanpa penambahan unsur apapun. Paduan aluminium untuk pembuatan screw akan dicor dengan menggunakan cetakan pasir (sand casting) pada 3 jenis variasi pemanasan suhu cetakan yaitu $200^{\circ} \mathrm{C}$ dan $300^{\circ} \mathrm{C}$. Pengujian yang dilakukan untuk mengetahui sifat-sifat mekanis dan fisis paduan aluminium tersebut yaitu pengujian tarik (Tensile Strngth), kekerasan (Hardeness), dan metalografi dengan mikroskop optik. Hasil pengujian maksimum terjadi pada bahan paduan $\mathrm{Al}-\mathrm{Si}$ dengan penambahan $\mathrm{TiB} 0,02 \%$ dan pemanasan suhu cetakan $400^{\circ} \mathrm{C}$ menghasilkan tegangan tarik maksimum sebesar 628,86 $\mathbf{N} / \mathbf{m m}^{2}$, sedangkan untuk pengujian kekerasan Vickers Hardness Number (VHN) menghasilkan angka kekerasan sebesar 114 $\mathrm{Kg} / \mathrm{mm}^{2}$; dan untuk hasil metalografi diperoleh data struktur yang terbentuk adalah fase hypereutectic silikon yang membentuk fasa silikon primer. Fasa tersebut memberikan ketahanan aus yang tinggi. Dengan demikian, terbukti bahwa paduan $\mathrm{Al}-\mathrm{Si}$ tersebut diatas dapat memperbaiki sifat-sifat Aluminium untuk pembuatan poros berulir (screw).

Kata kunci--- Aluminium paduan, Poros berulir (screw), Sifat mekanik dan fisik

\section{Pendahuluan}

Aluminium merupakan salah satu bahan non ferro yang sangat banyak dimanfaatkan dalam kehidupan sehari-hari, baik pada kalangan industri besar dan kecil maupun pada kalangan rumah tangga. Aluminium mempunyai sifat yang sangat menguntungkan yaitu : ringan $(1 / 3$ berat baja, tembaga, kuningan), tahan korosi sehingga dapat digunakan di hampir segala lingkungan seperti di lingkungan atmosfer, air (termasuk air garam), minyak dan banyak zat kimia lainnya [1].

Komposisi paduan dan pemilihan proses pada saat pengecoran dapat mempengaruhi struktur mikro dari aluminium paduan. Struktur mikro dapat dirubah dengan penambahan unsur tertentu dari paduan Al-Si yang dapat memperbaiki sifat mampu cor (castability), sifat mekanis dan mampu mesin yang baik (machinability) [2].

Ukuran butir dari aluminium paduan tergantung pada jumlah inti yang terbentuk dalam logam cair sebelum dimulainya solidifikasi. Titanium pada umumnya ditambahkan ke dalam logam cair sebesar 
0,02 sampai $0,15 \%$. TiB ini berfungsi sebagai penghalus butir (Grain refiner). TiB sangat penting sekali dalam memperbaiki sifat dari aluminium paduan seperti sifat mekanis, mengurangi porositas, lebih tahan terhadap retak panas (hot cracking), merubah struktur dan memperbaiki hasil akhir pada permukaannya [2].

Penelitian tentang paduan Al-Si telah banyak dilakukan oleh peneliti sebelumnya. Sulung Andi F, [3] meneliti paduan $75 \%$ Al-25\% Si dengan menggunakan dapur lebur atau krusibel. Pengecoran aluminium paduan dengan variasi tekanan angin $0,3,4$ dan 5 Psi menggunakan kompresor dan didapatkan hasil yang lebih baik pada tekanan 5 Psi yaitu $13,66 \mathrm{Kg} / \mathrm{mm}^{2}$ sedangkan tanpa tekanan didapatkan hasil 10,15 $\mathrm{Kg} / \mathrm{mm}^{2}$. Selanjutnya dengan adanya tekanan pada saat proses pengecoran akan meningkatkan nilai kekerasan sebesar BHN $163 \mathrm{Kg} / \mathrm{mm}^{2}$ dan juga mencegah adanya porositas atau cacat pada hasil coran.

Poros silinder berulir (screw) dan silinder penghancur yang diujungnya terpasang landasan pulley akan digerakkan oleh $V$-belt sebagai putaran transmisi dari putaran input motor ke sistem mekanisme penggilingan.

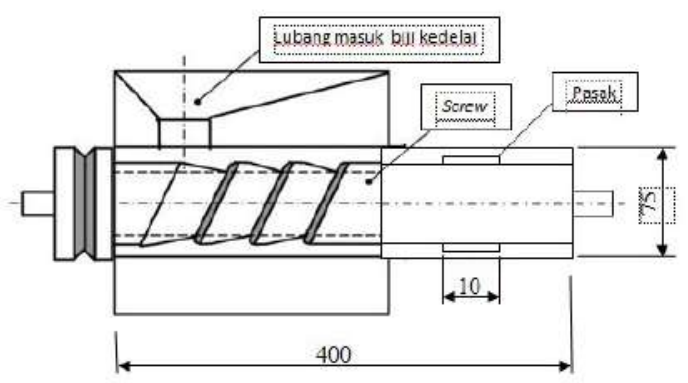

Gambar 1. Poros Berulir / Screw

Jenis pola yang dipilih dalam pembuatan screw ini adalah pola belah. Pola belah ini terdiri dari dua bagian yakni bagian atas yang disebut dengan kup dan bagian bawah disebut dengan drag.

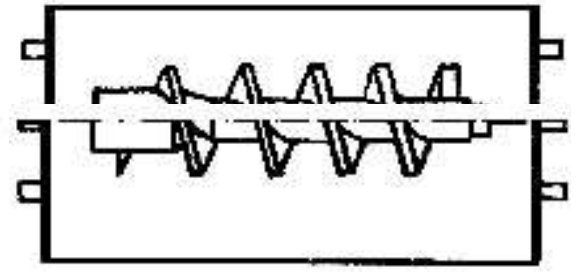

Gambar 2. Pola kup (bagian atas) dan drag (bagian bawah)

Cetakan pasir merupakan cetakan yang paling banyak digunakan, karena memiliki keunggulan :

1. Dapat mencetak logam dengan titik lebur yang tinggi, seperti baja, nikel dan titanium;

2. Dapat mencetak benda cor dari ukuran kecil sampai dengan ukuran besar;

3. Jumlah produksi dari satu sampai jutaan.

Agar ruang lingkup permasalahan tidak terlalu luas, maka penelitian ini mempunyai batasan-batasan permasalahan sebagai berikut :

1. Spesimen pengujian dibuat dari paduan Aluminium $50 \%$ Al profil dan 50\% piston bekas (Paduan Al-Si).

2. Pengecoran dengan menggunakan cetakan pasir (sandcasting) dengan pola kup dan drag yang dipanaskan atau pre heat dengan variasi suhu $200^{\circ} \mathrm{C}$, dan $300^{\circ} \mathrm{C}$.

3. Pada proses pengecoran TiB yang ditambahkan adalah sebesar $0,02 \%$.

Penelitian ini bertujuan untuk memperoleh pengetahuan tentang hubungan antara lain: Proses pengecoran dengan variasi suhu pemanasan cetakan pasir (sand cast) terhadap sifat mekanis, dan struktur mikro; Penambahan TiB terhadap sifat mekanis dan struktur mikro pada paduan $50 \% \mathrm{Al}-50 \% \mathrm{Si}$ dengan penambahan unsur $0,02 \%$ Ti-B.

\section{Metode Penelitian}

\section{A. Bahan}

Pelaksanaan penelitian ini digunakan adalah aluminium profil bekas dan aluminium paduan $\mathrm{Si}$ diambil dari piston bekas. Inokulan sebagai penghalus butir menggunakan penambahan unsur TiB.

\section{B. Alat}

Beberapa alat yang digunakan antara lain :

Timbangan digital, digunakan untuk uji density 
Mesin uji tarik Servopulser Shimadzu, digunakan untuk menguji tarik dari suatu material. Mesin uji kekerasan, menggunakan uji kekerasan mikro vickers untuk mengetahui kekerasan bahan.

Mikroskop optik, untuk pengamatan struktur mikro dari suatu material dengan perbesaran yang dipakai pada mikroskop $100 \mathrm{X}$.

\section{Tempat Penelitian}

Pelaksanaan pembuatan bahan (specimen) pengecoran dilakukan di IKM Pengecoran Logam, Nitikan, Yogyakarta. Pengujian bahan dilakukan di laboratorium bahan, Departemen Teknik Mesin dan Industri Fakultas Teknik, Universitas Gadjah Mada Yogyakarta.

\section{Metode}

Dalam penelitian ini dilakukan proses pengecoran aluminium profil dan aluminium dari piston bekas yang mengandung unsur silikon dengan penambahan unsur Ti-B sebagai penghalus butir. Pengamatan yang dilakukan adalah struktur mikro dan sifat mekanik yang terjadi akibat dari variasi suhu cetakan 200 dan $300^{\circ} \mathrm{C}$.

\section{E. Proses Pengecoran}

Langkah awal sebelum proses pengecoran adalah membuat pola atau cetakan dari pasir (sand cast). Penentuan kup, drag dan permukaan pisah harus mempertimbangkan beberapa hal sebagai berikut:

a) Pola harus mudah dikeluarkan dari cetakan

b) Penempatan inti harus mudah dan dibuat secara teliti

c) Sistem saluran harus dapat mengalirkan logam cair dengan mudah dan hasilnya optimum.

Bahan-bahan yang dipakai untuk pembuatan pola adalah kayu, resin atau logam. Dalam hal tertentu atau pemakaian khusus juga bisa dipakai bahan seperti plester atau lilin. Pola yang telah dibentuk difinishing dengan menggunakan amplas no.1000 agar permukaannya lebih halus. Hal ini untuk mencegah agar serat kayu tidak lengket dengan pasir yang dapat merusak cetakan. Proses peleburan dimulai dengan memasukkan bahan baku aluminium. Setelah aluminium mencair, kemudian dimasukkan potongan-potongan piston bekas dan Ti-B. Setelah seluruh bahan ini mencair secara homogen diperiksa komposisinya, bila komposisi dari logam cair telah sesuai dengan yang diharapkan dan temperaturnya telah mencapai temperatur yang diharapkan $\left(660^{\circ} \mathrm{C}\right)$ maka logam cair telah dapat dituang.

\section{F. Pengujian Tarik}

Sifat mekanik yang dipelajari adalah kekuatan tarik. Pengujian tarik dilakukan untuk mengetahui tegangan tarik, tegangan luluh dan regangan pada bahan pembuatan poros berulir (screw). Pengujian dilakukan sesuai dengan standar JIS Z 2201 [4] dengan ukuran sampel seperti yang ditunjukkan pada Gambar 3. Kekuatan tarik merupakan kemampuan bahan untuk menerima beban tarik. Pengujian dilakukan dengan menggunakan mesin uji tarik Servopulser Shimadzu dengan cara menjepit sampel dengan kuat dan beban diberikan secara kontinyu sampai sampel tersebut putus. Sifat-sifat mekanis yang diharapkan untuk diketahui adalah kekuatan (tegangan) tarik, kekuatan luluh dan regangan dengan perhitungan menggunakan rumus: (1)(2)

$$
\sigma u=\frac{P u}{A o}
$$

$$
\begin{array}{ll}
\text { бu } & : \text { Tegangan Tarik }\left(\mathrm{N} / \mathrm{mm}^{2}\right) \\
\mathrm{Pu} & : \text { Beban Tarik }(\mathrm{KN}) \\
\mathrm{Ao} & \text { : Luas Penampang Tarik Mula- } \\
& \text { mula }\left(\mathrm{mm}^{2}\right) \\
& \varepsilon=\frac{L-L o}{L o} \times 100 \%
\end{array}
$$

$$
\begin{array}{ll}
\varepsilon & : \text { Regangan }(\%) \\
\text { Lo } & \text { : Panjang Awal Spesimen }(\mathrm{mm}) \\
\text { L } & \text { : Panjang Akhir Spesimen }(\mathrm{mm})
\end{array}
$$

\section{G. Pengujian Metalografi}

Pengamatan perubahan struktur mikro akibat pengaruh variasi suhu cetakan diamati dengan pengujian metalografi yang dilakukan pada spesimen uji. Pengujian dilakukan dengan cara memotong sampel sesuai ukuran kemudian dibingkai dengan resin dan selanjutnya dilakukan pemolesan. Penggerindaan dilakukan dengan kertas amplas yang bertingkat 
kekasarannya sedangkan pemolesan dilakukan dengan pasta alumina. Sampel yang telah mengkilap dietsa dengan larutan etsa asam nital 3\% untuk selanjutnya diamati struktur mikronya dengan mikroskop optik.

\section{H. Pengujian Kekerasan}

Pengujian kekerasan dimaksudkan untuk mendapatkan data perubahan kekerasan dari bahan akibat adanya pengelasan. Pengujian dilakukan dengan mesin uji keras (Vickers Hardness Testing Machine) dengan cara melakukan penekanan pada sampel menggunakan penekan berbentuk piramida intan yang dasarnya bujur sangkar. Besarnya sudut puncak identor piramida intan 1360. Besarnya angka kekerasan dihitung berdasarkan persamaan

$\mathrm{HVN}=1,8544 \times \mathrm{P} / \mathrm{d} 2$

HVN : Angka kekerasan Vickers

(Hardness Vickers Number )

$\mathrm{P}$ : Beban yang digunakan $(\mathrm{kg})$

$\mathrm{d}$ : Diagonal identasi ( $\mathrm{mm}$ )

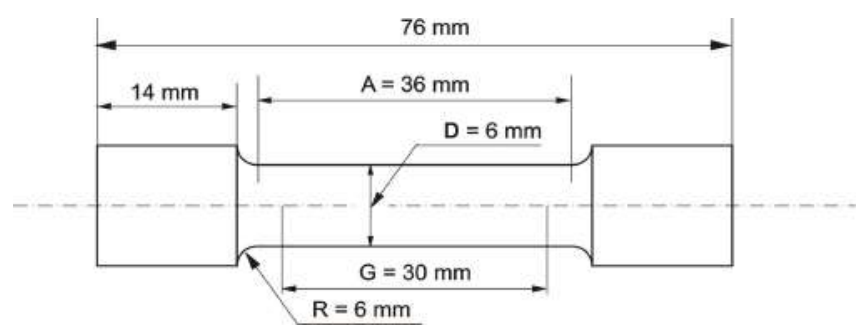

Gambar 3. Spesimen uji tarik

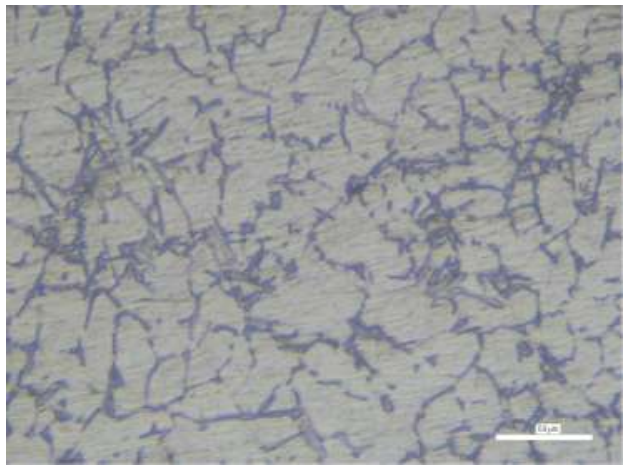

Gambar 4. Struktur Mikro (Raw Material)

\section{Hasil dan Pembahasan}

Hasil Penelitian tentang pembuatan poros berulir (Screw) berbahan dasar 50\% aluminium bekas dan 50\% piston bekas dengan penambahan unsur $0,02 \% \mathrm{TiB}$ didapatkan perubahan struktur mikro dan sifat mekanis sebagai berikut :

Pembuatan spesimen dilakukan dengan proses pengecoran metode sand casting atau menggunakan cetakan pasir. Bahan yang digunakan adalah piston bekas dan aluminium profil. Proses pengecoran dilakukan dengan variasi suhu cetakan yaitu : $200^{\circ}$ dan $300^{\circ} \mathrm{C}$.

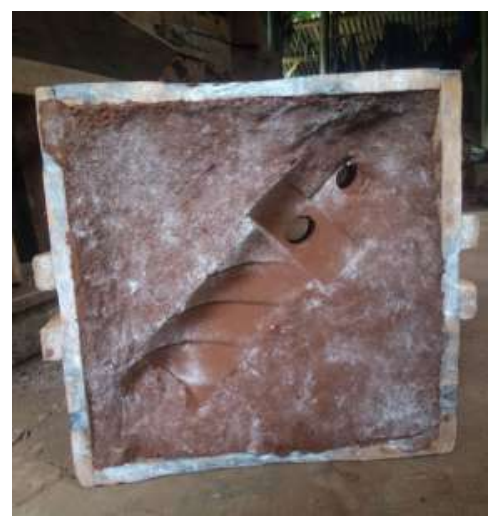

Gambar 5. Cetakan Atas (Cup)

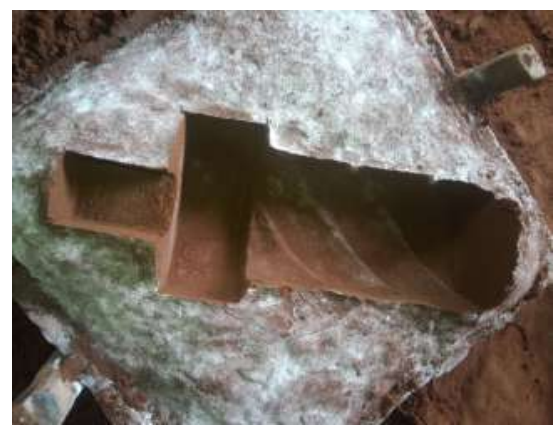

Gambar 6. Cetakan Bawah (drag)

Logam coran dalam proses pengecoran ini di lebur dalam tungku peleburan dengan bahan bakar solar. Tungku ini hanya mempunyai satu ruangan yaitu daerah kruss untuk tempat mencairkan logam dan sekaligus menjadi tempat logam yang akan dicairkan atau dengan kata lain logam cair dan logam yang akan dicairkan terdapat dalam ruangan yang sama. Bagian atas dari tungku ini terbuka lebar, sehingga memudahkan pengisian logam yang akan dilebur. Proses peleburan 
dimulai dengan memasukkan bahan baku aluminium. Setelah aluminium mencair, kemudian dimasukkan potongan-potongan piston bekas dan Ti-B. Setelah seluruh bahan ini mencair secara homogen diperiksa komposisinya, bila komposisi dari logam cair telah sesuai dengan yang diharapkan dan temperaturnya telah mencapai temperatur yang diharapkan $\left(660^{\circ} \mathrm{C}\right)$ maka logam cair telah dapat dituang.

Tabel 1. Komposisi Bahan baku Peleburan

\begin{tabular}{|c|c|c|c|}
\hline \multirow{2}{*}{ Keterangan } & \multicolumn{3}{|c|}{$\begin{array}{c}\text { Komposisi Bahan Pembuat } \\
\text { Screw }\end{array}$} \\
\cline { 2 - 4 } & Aluminium & $\begin{array}{l}\text { Piston } \\
\text { bekas }\end{array}$ & Ti-B \\
\hline$\%$ & 50 & 50 & 0,02 \\
\hline $\mathrm{Kg}$ & 7 & 7 & 0,14 \\
\hline
\end{tabular}

Pengujian tarik dilakukan untuk mengetahui deformasi plastis yang terjadi pada spesimen untuk bahan pembuatan poros berulir (screw). Pada logamlogam coran tidak terdapat pengecilan penampang setempat sampai bahan logam tersebut patah hal ini disebabkan karena struktur butiran benda cor lebih kasar dibandingkan dengan pembentukan material dengan proses lain, sifat mekanik logam yang demikian menunjukkan bahwa logam hasil coran tersebut tidak dapat dibentuk atau dideformasi plastis.

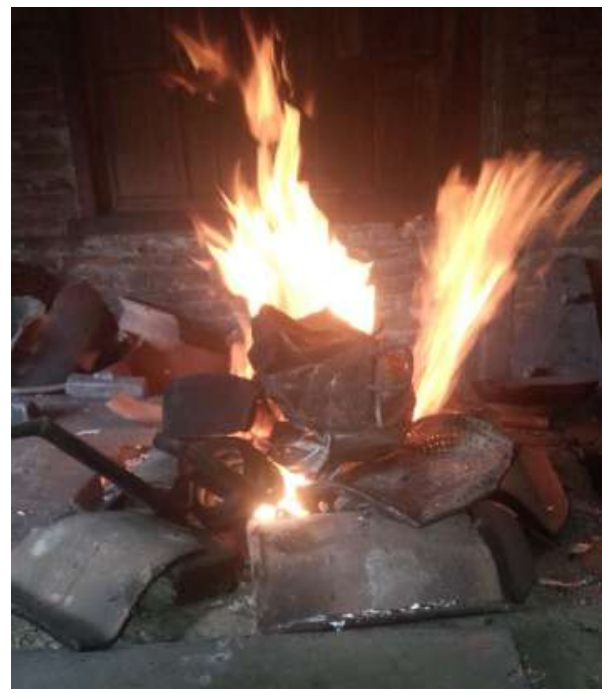

Gambar 7. Proses Peleburan
Mutu dari suatu produk pengecoran tergantung dari keadaan (kondisi) logam cair yang digunakan dalam proses pencetakan, karena semakin baik komposisi dari logam cair, semakin baik mutu dari hasil corannya. Semakin homogen logam cair, semakin baik hasil corannya.

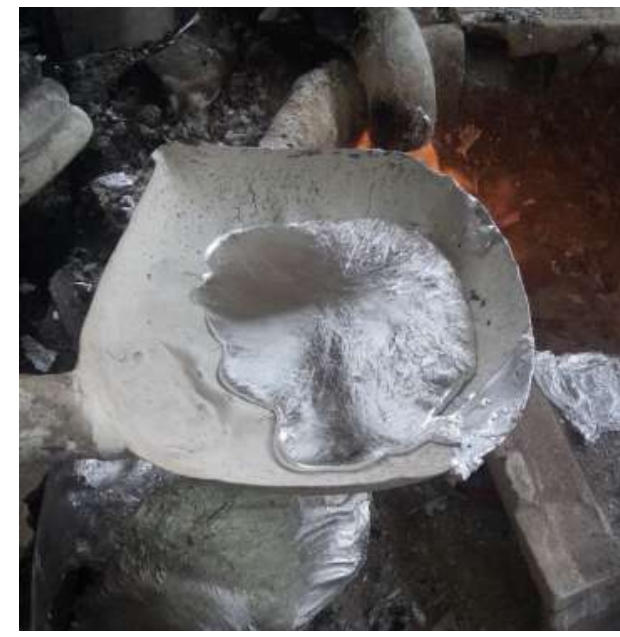

Gambar 8. Hasil Peleburan

Pada Grafik dibawah (Gambar 9) dapat dilihat bahwa nilai rata-rata kekuatan tarik pada pemanasan suhu cetakan $200^{\circ} \mathrm{C}$ adalah $565,763 \mathrm{~N} / \mathrm{mm}^{2}$ dan pada suhu pemanasan cetakan $300^{\circ} \mathrm{C}$ adalah $567,03 \mathrm{~N} / \mathrm{mm}^{2}$. Data tersebut diatas menunjukkan bahwa perlakuan pemanasan cetakan $300^{\circ} \mathrm{C}$ dengan penambahan $0,02 \%$ TiB menghasilkan tegangan tarik lebih tinggi dibandingkan dengan variasi Ti-B $200^{\circ} \mathrm{C}$. Sehingga pada pengujian ini menunjukan sifat material untuk pembuatan poros berulir (screw) merupakan bahan paduan yang kuat dan tahan aus.

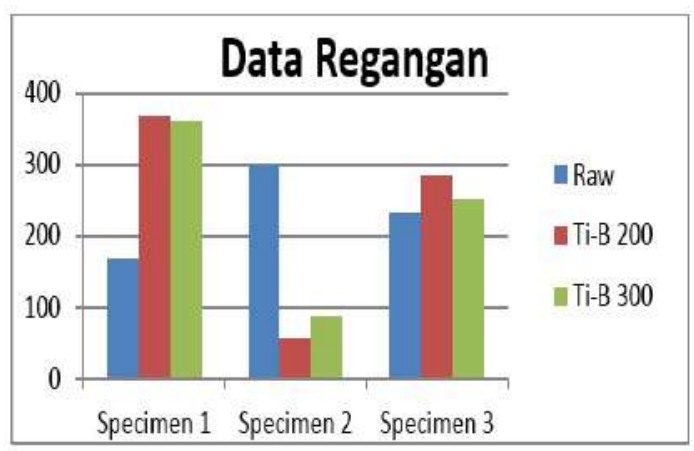

Gambar 9. Grafik Regangan Tarik 
Tabel 2. Hasil Pengujian Tarik, untuk specimen dengan suhu pre heat cetakan $200^{\circ} \mathrm{C}$

\begin{tabular}{|c|c|c|c|c|c|c|c|c|c|}
\hline Pengujian & $\begin{array}{c}\text { Kode } \\
\text { specimen }\end{array}$ & $\begin{array}{l}\text { Lebar } \\
(\mathrm{mm})\end{array}$ & $\begin{array}{l}\text { Tebal } \\
(\mathrm{mm})\end{array}$ & $\begin{array}{c}\text { Tegangan } \\
\text { Tarik } \\
(\sigma u) \\
\left(\mathrm{N} / \mathrm{mm}^{2}\right)\end{array}$ & $\begin{array}{c}\text { Panjang } \\
\text { Awal } \\
\text { (Lo) } \\
\text { (mm) }\end{array}$ & $\begin{array}{c}\text { Panjang } \\
\text { Akhir } \\
(\mathrm{Lf}) \\
(\mathrm{mm})\end{array}$ & $\begin{array}{c}\text { Beban } \\
\text { Maksimal } \\
(K N)\end{array}$ & $\begin{array}{l}\text { Pertambahan } \\
\text { Panjang }(\Delta t)\end{array}$ & $\begin{array}{c}\text { Regangan } \\
(\varepsilon) \\
(\%)\end{array}$ \\
\hline 1 & $\begin{array}{c}\text { Ti-B } \\
200^{\circ} \mathrm{C}\end{array}$ & 6,94 & 5,90 & 488,4 & 25 & 25,92 & 20 & 0,92 & 3,68 \\
\hline 2 & $\begin{array}{c}\text { Ti-B } \\
200^{\circ} \mathrm{C}\end{array}$ & 6,02 & 5,63 & 590,09 & 25 & 25,14 & 20 & 0,14 & 0,56 \\
\hline 3 & $\begin{array}{c}\text { Ti-B } \\
200^{\circ} \mathrm{C}\end{array}$ & 5,65 & 5,72 & 618,8 & 25 & 25,71 & 20 & 0,71 & 2,84 \\
\hline
\end{tabular}

Tabel 3. Hasil Pengujian Tarik, untuk specimen dengan suhu pre heat cetakan $300^{\circ} \mathrm{C}$

\begin{tabular}{|c|c|c|c|c|c|c|c|c|c|}
\hline Pengujian & $\begin{array}{c}\text { Kode } \\
\text { specimen }\end{array}$ & $\begin{array}{c}\text { Lebar } \\
(\mathrm{mm})\end{array}$ & $\begin{array}{l}\text { Tebal } \\
(\mathrm{mm})\end{array}$ & $\begin{array}{c}\text { Tegangan } \\
\text { Tarik } \\
(\sigma u) \\
\left(\mathrm{N} / \mathrm{mm}^{2}\right)\end{array}$ & $\begin{array}{c}\text { Panjang } \\
\text { Awal } \\
\text { (Lo) } \\
\text { (mm) }\end{array}$ & $\begin{array}{c}\text { Panjang } \\
\text { Akhir } \\
(\mathrm{Lf}) \\
(\mathrm{mm})\end{array}$ & $\begin{array}{c}\text { Beban } \\
\text { Maksimal } \\
(K N)\end{array}$ & $\begin{array}{l}\text { Pertambahan } \\
\text { Panjang }(\Delta t)\end{array}$ & $\begin{array}{c}\text { Regangan } \\
(\varepsilon) \\
(\%)\end{array}$ \\
\hline 1 & $\begin{array}{c}\mathrm{Ti}-\mathrm{B} \\
300^{\circ} \mathrm{C}\end{array}$ & 6,04 & 5,60 & 591,2 & 25 & 25,9 & 20 & 0,9 & 3,6 \\
\hline 2 & $\begin{array}{c}\text { Ti-B } \\
300^{\circ} \mathrm{C}\end{array}$ & 6,05 & 5,60 & 590,3 & 25 & 25,22 & 20 & 0,22 & 0,88 \\
\hline 3 & $\begin{array}{c}\text { Ti-B } \\
300^{\circ} \mathrm{C}\end{array}$ & 6,86 & 5,61 & 519,6 & 25 & 25,63 & 20 & 0,63 & 2,52 \\
\hline
\end{tabular}

Tabel 4. Data Pengujian Kekerasan (Vickers Hardness Number)

\begin{tabular}{|c|c|c|c|c|c|c|c|}
\hline \multirow{2}{*}{ No } & \multirow{2}{*}{ Kode Spesimen } & \multicolumn{2}{|c|}{ Titik Pengujian } & \multirow{2}{*}{$P$ (gr.f) } & \multirow{2}{*}{$\mathrm{t}(\mathrm{sec})$} & \multirow{2}{*}{$\mathrm{d}^{2}(\mathrm{~mm})$} & \multirow{2}{*}{$\mathrm{VHN}\left(\mathrm{Kg} / \mathrm{mm}^{2}\right)$} \\
\hline & & $\mathrm{d} 1(\mu \mathrm{m})$ & $\mathrm{d} 2(\mu \mathrm{m})$ & & & & \\
\hline \multirow{3}{*}{1} & \multirow{3}{*}{ Raw } & 46,3 & 46,8 & 100 & 15 & 2,167 & 86 \\
\hline & & 47,5 & 47,9 & 100 & 15 & 2,275 & 81 \\
\hline & & 48 & 48,5 & 100 & 15 & 2,328 & 80 \\
\hline \multicolumn{6}{|c|}{ Rata-rata } & VHN & 82 \\
\hline \multirow{3}{*}{2} & \multirow{3}{*}{200} & 43,4 & 44 & 100 & 15 & 1,910 & 97 \\
\hline & & 48 & 48,5 & 100 & 15 & 2,328 & 80 \\
\hline & & 43,3 & 43,5 & 100 & 15 & 1,884 & 98 \\
\hline \multicolumn{6}{|c|}{ Rata-rata } & VHN & 92 \\
\hline \multirow{3}{*}{3} & \multirow{3}{*}{300} & 42 & 42 & 100 & 15 & 1,764 & 105 \\
\hline & & 43 & 43,2 & 100 & 15 & 1,858 & 100 \\
\hline & & 42,4 & 42,3 & 100 & 15 & 1,794 & 103 \\
\hline \multicolumn{6}{|c|}{ Rata-rata } & VHN & 103 \\
\hline
\end{tabular}




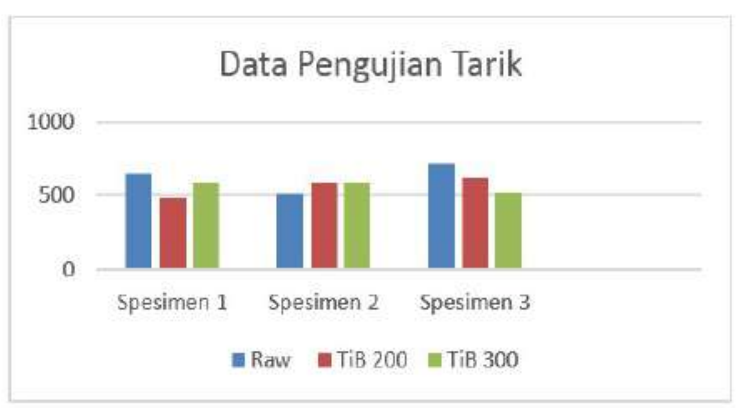

Gambar 10. Grafik Tegangan Tarik

Pengamatan perubahan struktur mikro akibat pengelasan diamati dengan pengujian metalografi yang dilakukan pada daerah logam induk. Pengujian dilakukan dengan cara memotong sampel sesuai ukuran kemudian dibingkai dengan resin dan selanjutnya dilakukan pemolesan. Penggerindaan dilakukan dengan kertas amplas yang bertingkat kekasarannya sedangkan pemolesan dilakukan dengan pasta alumina. Sampel yang telah mengkilap dietsa dengan larutan etsa asam nital 3\% untuk selanjutnya diamati struktur mikronya dengan mikroskop optik. Diagram fasa dibawah ini (gambar 10) menunjukkan paduan antara aluminium dan silikon yang digunakan pada bahan pembuatan poros berulir (screw). Paduan hypoeutectic Al-Si mengandung unsur $\mathrm{Si}$ sebesar $<12,6 \%$, sedangkan paduan eutectic mengandung unsur $\mathrm{Si}$ sebesar $12 \%$. Untuk paduan hypereutectic mengandung unsur Si sebesar $>12,6 \%$.

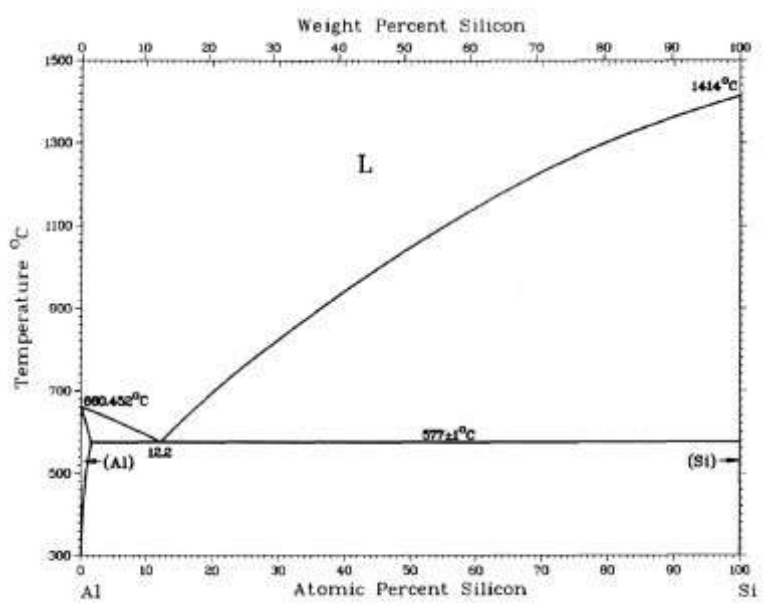

Gambar 11. Diagram Fasa Al-Si

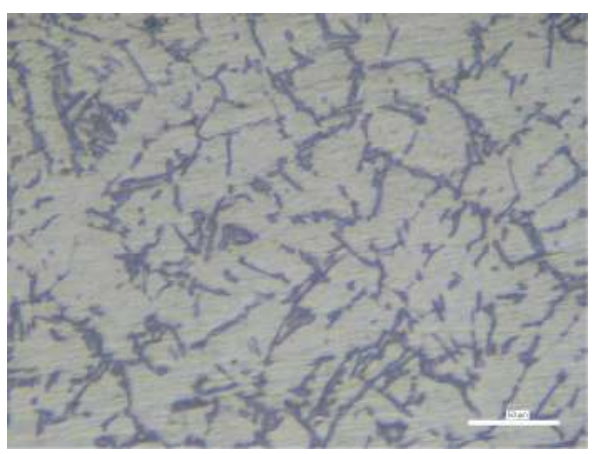

Gambar 12. Struktur Mikro Spesimen Al-Si + TiB dengan suhu pemanasan cetakan $200^{\circ} \mathrm{C}$

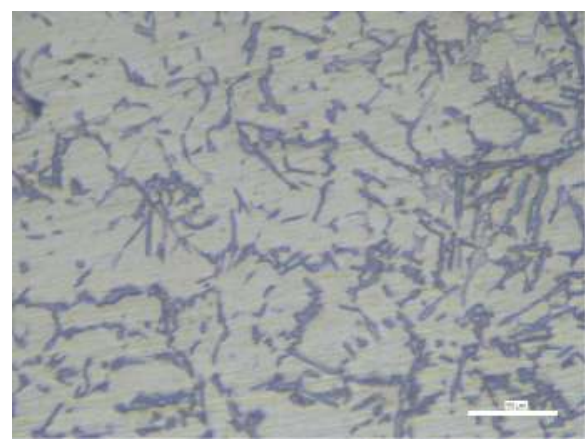

Gambar 13. Struktur Mikro Spesimen Al-Si + TiB dengan suhu pemanasan cetakan $300^{\circ} \mathrm{C}$

Berdasarkan hasil pengujian struktur mikro pada aluminium paduan daur ulang dengan menggunakan cetakan pasir untuk pembuatan poros berulir (screw) terbentuk beberapa fasa, diantaranya fasa $\mathrm{Al}$ dan fasa $\mathrm{Al}-$ Si. Adapun karakteristik dari fasa-fasa tersebut adalah sebagai berikut:

1. Fasa Al (berwarna terang) adalah larutan padat primer.

2. Al-Si (berwarna kelabu terang). Fasa ini terbentuk karena jumlah prosentase silikon $(\mathrm{Si})$ lebih besar dari magnesium (Mg). Pada umumnya akan dapat meningkatkan tingkat kekerasan dan dapat menghambat laju korosi. 
Hasil penelitian tentang perubahan struktur mikro dan sifat mekanik akibat perlakuan pemanasan cetakan ditunjukkan pada gambar diatas. Struktur mikro paduan aluminium hasil pengamatan dengan mikroskop optik pada perbesaran 100 kali ditunjukkan pada Gambar 10; 11 dan 12 Pada Gambar 12 hasil uji metalografi diperoleh data struktur yang terbentuk pada suhu pemanasan cetakan $400^{\circ} \mathrm{C}$ dengan penambahan unsur $0,02 \% \mathrm{TiB}$ adalah struktur yang terbentuk adalah fase hypereutectic silikon yang membentuk fasa silikon primer. Fasa tersebut memberikan ketahanan aus yang tinggi dan porositas yang rendah.

Penghalusan butir memberikan pengaruh positif pada pembentukan poros berulir (screw) antara lain:

1. Distribusi porositas; Ketika penghalus butir digunakan dapat mengurangi jumlah porositas yang terjadi. Penambahan penghalus butir dapat memproduksi distribusi porositas yang baik secara seragam.

2. Distribusi intermetalik; Pada paduan yang mengandung fasa eutektik dengan jumlah yang banyak, seperti Al-Si, tidak diharapkan bahwa penghalus butir akan mempengaruhi distribusi fasa intermetalik. Fasa intermetalik merupakan fasa kedua yang mengendap pada struktur mikropaduan aluminium paduan, yang terbentuk sebagai akibat dari komposisi kimia yangmelebihi batas kelarutannya. Keberadaan fasa ini sangat dipengaruhi oleh komposisidan mekanisme pembentukan yang terjadi.

3. Sifat mekanik; Sifat seperti kekuatan tarik dan elongasi meningkat dengan adanya penghalus butir. Pada paduan Al-Si yang utama adalah meningkatkan distribusi porositas.

Pada pengujian kekerasan spesimen untuk material bahan pembuatan poros berulir (screw) menggunakan uji kekerasan vickers (Vickers Hardness Number). Dari hasil uji kekerasan pada paduan hasil pengecoran Industri kecil yang telah ditambah unsur terjadi kenaikan angka kekerasan jika dibandingkan dengan hasil pengecoran industri kecil. Kenaikan ini cukup signifikan sehingga kekerasan permukaan material yang telah ditambah unsur mendekati nilai kekerasan permukan material produk industri. Kenaikan ini kurang maksimal hal ini disebabkan karena karena adanya porositas pada saat pengecoran, teknik pengecoran dan pembentukan material (pencetakan), sistim cetak yang mengunakan cetak pasir dengan mengandalkan gaya gravitasi sangat besar pengaruhnya terhadap sifat mekanik bahan. Untuk paduan yang mengalami perlakuaan panas terlihat angka kekerasan yang meningkat, angka kekerasan ini juga dipengaruhi oleh media pendingin.

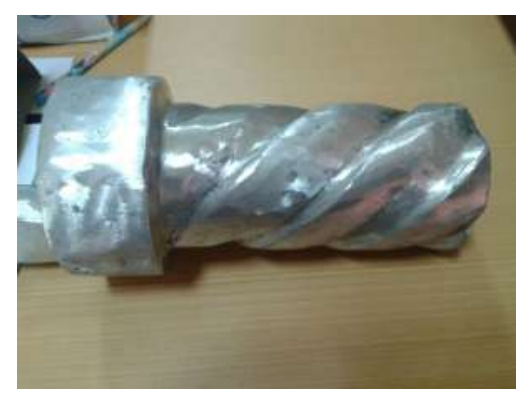

Gambar 14. Screw

Kekerasan pada spesimen paduan $\mathrm{Al}-\mathrm{Si}+\mathrm{TiB}$ yang mengalami proses pemanasan cetakan dengan suhu $300^{\circ} \mathrm{C}$ untuk pembuatan poros berulir (screw) memiliki nilai kekerasan yang tinggi, dibanding pada variasi suhu pemanasan cetakan yang lainnya. Ini berarti semakin tinggi nilai tegangan tarik, maka semakin tinggi pula angka kekerasannya.

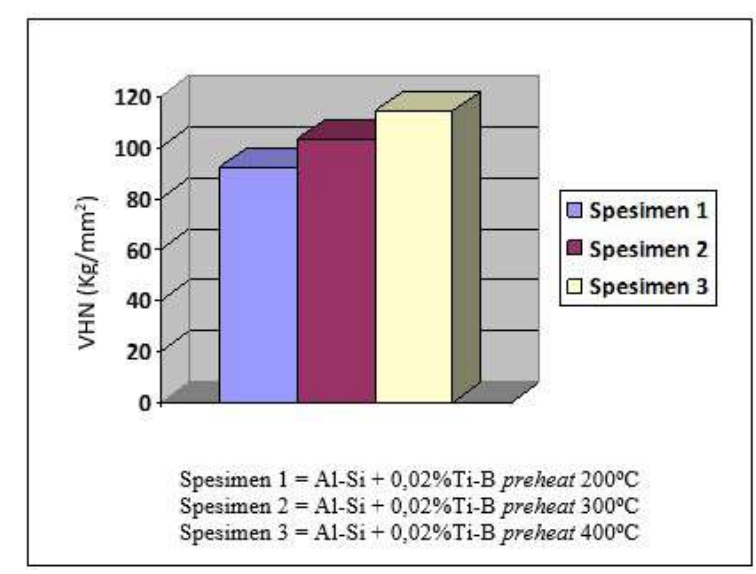

Gambar 14. Grafik Kekerasan Vickers 


\section{Kesimpulan}

Hasil simpulan yang didapat dari penelitian ini adalah bahwa proses pengecoran untuk pembuatan poros berulir (screw) dengan variasi suhu pemanasan cetakan $200^{\circ} \mathrm{C}$; dan $300^{\circ} \mathrm{C}$ didapatkan bahwa pada pengecoran tuang dengan menggunakan cetakan pasir dengan dimensi cetakan lebar $75 \mathrm{~mm}$, dan panjang $400 \mathrm{~mm}$ terjadi ketidakmerataan sifat mekanis pada tiap lapisan atau bagian, hal ini disebabkan oleh kecepatan pendinginan yang berbeda antara logam cair dengan cetakan pasir, udara dan bagian tengah yang tidak bersentuhan dengan lingkungan. Hasil pengujian maksimum terjadi pada bahan paduan Al-Si dengan penambahan $\mathrm{TiB} 0,02 \%$ dan pemanasan suhu cetakan $300^{\circ} \mathrm{C}$ menghasilkan tegangan tarik maksimum sebesar $567,03 \mathrm{~N} / \mathrm{mm}^{2}$, sedangkan untuk pengujian kekerasan Vickers Hardness Number (VHN) menghasilkan angka kekerasan sebesar $103 \mathrm{Kg} / \mathrm{mm}^{2}$; dan untuk hasil metalografi diperoleh data struktur yang terbentuk adalah fase hypereutectic silikon yang membentuk fasa silikon primer. Fasa tersebut memberikan ketahanan aus yang tinggi dan porositas yang rendah. Dengan demikian, terbukti bahwa paduan Al-Si tersebut diatas dapat memperbaiki sifat-sifat Aluminium untuk pembuatan poros berulir (screw). Saran atau masukan dari penelitian ini adalah Perlu adanya persiapan spesimen uji yang lebih banyak untuk menghindari kegagalan pada saat pengujian berlangsung. Pada penelitian dengan menggunakan paduan aluminium ini, dapat dikembangkan untuk diaplikasikan pada beberapa komponen-komponen mesin yang lain selain pada poros berulir (screw). Jika diaplikasikan untuk industri kecil yang berbasis makanan, perlu adanya standar kesehatan untuk penggunaan komponen mesin dengan bahan logam. Selain itu juga perlu dilakukan uji komposisi bahan terlebih dahulu untuk mengetahui komposisi yang spesifik dari bahan pembuatan poros berulir ini.

\section{Ucapan Terima Kasih}

Pada kesempatan ini, penulis ingin mengucapkan terimakasih yang sebesar-besarnya kepada Koordinator Kopertis Wilayah V, Daerah Istimewa Yogyakarta atas bantuannya dalam pendanaan penelitian ini melalui dana penelitian dosen pemula DIPA Kopertis V DIY.

\section{Daftar Pustaka}

[1] Surdia, T dan Saito, S., 1992, "Pengetahuan Bahan Teknik", P.Tpradnya Paramitha, Jakarta.

[2] Brown, J.R., 1999, "Foseco Non-Ferrous Foundryman's Handbook", Butterworth Heinemann, Eleventh Edition, Oxford.

[3] Sulung Andi F, 2005., "Pengaruh Tekanan Saat Pengecoran Aluminium paduan terhadap Kualitas Hasil Coran" Tugas Akhir UGM.

[4] JIS Handbook Non Ferrous Metal and Metallurgy, 1977, Japanese Standards Association 